\title{
Validation of the Portuguese Version of the Postoperative Quality Recovery Scale (PostopQRS)
}

\author{
Validação da Versão Portuguesa da Escala da Qualidade \\ da Recuperação Pós-Operatória (PostopQRS)
}

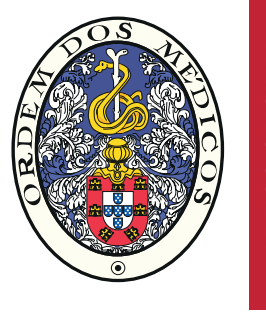

\author{
André BISCAIA ه1, Pedro AMORIM², Simão ESTEVES², Filipa LAGARTO², Blandina GOMES², José BISMARCK², \\ Nuno RODRIGUES ${ }^{3}$, Mafalda NOGUEIRA ${ }^{4}$, Colin F. ROYSE \\ Acta Med Port 2018 Oct;31(10):551-561 - https://doi.org/10.20344/amp.9451
}

\section{ABSTRACT}

Introduction: The Postoperative Quality Recovery Scale is a brief instrument of six domains designed to assess quality of recovery from early to long term after surgery. This study aims to validate the Portuguese version of the Postoperative Quality Recovery Scale. Material and Methods: In this observational study 101 adult patients undergoing elective surgery completed the Postoperative Quality Recovery Scale at 15 minutes and 40 minutes, one and three days after surgery. Three constructs were assessed for validity: increased recovery over time; effect of gender and recovery association with muscle strength. Reliability, responsiveness, feasibility and acceptability were also assessed.

Results: Construct validity was shown by increased recovery over time; worse recovery for female patients in emotive, nociceptive, activities of daily living and overall recovery; improved muscle strength in recovered patients. Internal consistency for activities of daily living was acceptable at all-time points (Cronbach's $\alpha$ value of 0.772 or higher), indicating scale reliability. The scale was able to detect differences in postoperative quality of recovery between the neuromuscular blockade reversal agents, neostigmine and sugammadex, indicating scale responsiveness. The time to conduct the Portuguese version at baseline was $95-581$ seconds (median 319 seconds) and it was reduced with subsequent assessments. The proportion of patients completing all scale items was $87 \%, 75 \%, 65 \%$ and $94 \%$ for the four time periods evaluated, indicating scale feasibility and acceptability.

Discussion: This study shows that the Portuguese version of the Postoperative Quality Recovery Scale, demonstrates construct validity, reliability, responsiveness, feasibility and acceptability.

Conclusion: This study allowed validation of the Portuguese version of the Postoperative Quality Recovery Scale.

Keywords: Anesthesia Recovery Period; Neuropsychological Tests; Portugal; Postoperative Period; Recovery of Function; Surveys and Questionnaire

\section{RESUMO}

Introdução: A Escala da Qualidade da Recuperação Pós-Operatória é um instrumento de seis domínios, desenhada para avaliar a qualidade da recuperação no período pós-operatório precoce e tardio. Este estudo teve como objetivo validar a versão portuguesa da Escala da Qualidade da Recuperação Pós-Operatória.

Material e Métodos: Neste estudo observacional foi obtida uma amostra de 101 doentes adultos submetidos a cirurgia eletiva e que preencheu a Escala da Qualidade da Recuperação Pós-Operatória aos 15 e 40 minutos, um e três dias após a cirurgia. Três teorias foram avaliadas para aferir a validade teórica da escala: aumento da recuperação ao longo do tempo, efeito do género e a associação da recuperação com a força muscular. Foram também avaliadas a fiabilidade, poder de resposta, viabilidade e aceitabilidade.

Resultados: A validade teórica foi demonstrada pelo aumento da recuperação ao longo do tempo, assim como uma pior recuperação para doentes do sexo feminino em atividades emotivas, nociceptivas, diárias e de recuperação geral. Detetou-se ainda uma melhoria da força muscular em doentes recuperados. A coerência interna no domínio das atividades da vida diária foi aceitável em todos os tempos (valor a de Cronbach de 0,772 ou superior), indicando a fiabilidade da escala. Com esta escala foi possível detetar diferenças na qualidade pós-operatória da recuperação entre os agentes de reversão de bloqueio neuromuscular, a neostigmina e o sugammadex, indicando que a escala apresenta poder de resposta. O tempo para aplicar a versão portuguesa no período inicial (baseline) foi de 95 - 581 segundos (mediana 319 segundos) com uma diminuição em avaliações subsequentes. A proporção de doentes que completaram todos os itens da escala foi de $87 \%, 75 \%, 65 \%$ e $94 \%$ nos quatro períodos avaliados, indicando viabilidade e aceitabilidade da escala. Discussão: A versão portuguesa da Escala da Qualidade da Recuperação Pós-Operatória demonstrou ter validade, fiabilidade, poder de resposta, viabilidade e aceitabilidade.

Conclusão: Este estudo permitiu a validação da versão Portuguesa da Escala da Qualidade da Recuperação Pós-Operatória.

Palavras-chave: Inquéritos e Questionários; Período de Recuperação da Anestesia; Portugal; Período Pós-Operatório; Recuperação de Função Fisiológica; Testes Neuropsicológicos

\section{INTRODUCTION}

Postoperative recovery after surgery and anaesthesia has been traditionally evaluated by pain scores, physiological measures, recovery times, length of hospital stay, incidence

of adverse events (morbidity and mortality) or return to normal daily activities. ${ }^{1}$ These outcomes, however, are dependent on disease-specific or site-specific operative

\footnotetext{
1. Family Health Unit. Unidade de Saúde Familiar Marginal. ACES de Cascais. Cascais. Portugal.

2. Department of Anesthesiology. Hospital de Santo António. Porto. Portugal.

3. Department of Anesthesiology. Hospital da Luz. Lisboa. Portugal.

4. Merck Sharp \& Dohme, Lda. Paço de Arcos. Portugal.

5. Department of Surgery. The University of Melbourne. Melbourne. Australia.

6. Department of Anaesthesia and Pain Management. The Royal Melbourne Hospital. Carlton. Australia.

$\square$ Autor correspondente: André Biscaia. andre.rosa.biscaia@gmail.com

Recebido: 18 de julho de 2017 - Aceite: 18 de julho de 2018 | Copyright @ Ordem dos Médicos 2018
} 
procedures, as well as external factors, such as institutional practice, organizational structures and different health care systems-related circumstances. ${ }^{2,3}$ Quality is a central issue in the speciality of anaesthesia, ${ }^{4}$ and measurement of the quality of postoperative recovery from a patient perspective is recognised as an important outcome measure in scientific studies. ${ }^{1,5}$

Although there is still no agreement about a 'gold standard' on how to evaluate performance, recovery and patient satisfaction, several rating scales have been developed and validated to measure quality of recovery after anaesthesia and surgery, including the quality of recovery score-40 questionnaire (QoR-40) and its short form version (QoR-15) ${ }^{6-10}$ However, these patient-reported scales do not address cognitive recovery. This is a dimension known to be influenced by anaesthesia and increasingly recognized as a major morbidity factor but that may not fall within the patient's conscious experience. Furthermore, these instruments (QoR-40 and QoR-15) were primarily designed for inpatients and some aspects of care for these patients may not be applicable for ambulatory care. ${ }^{11}$

The Postoperative Quality Recovery Scale (PostopQRS) developed by Royse et $a^{12}$ is a brief instrument that enables the assessment of recovery over time from immediate recovery to long-term follow-up. The initial validation of the scale included baseline measurement before surgery and repeated measurements at 15 minutes (T15), 40 minutes (T40), day 1 (D1) and day 3 (D3) after surgery. The scale measures six recovery domains including physiological, nociceptive, emotive, cognitive, activities of daily living and overall patient perspective. Baseline measurements are critical to the use of the tool as the definition of recovery adopted by the PostopQRS group is "return to baseline values or better". PostopQRS is not a summative score, but is indicative of whether patients have either recovered or not, based on the return, at least, to the baseline in each of the domains. ${ }^{12}$ The scale has demonstrated correspondence to what is known and expected from the clinical experience. Moreover, the PostopQRS is able to discriminate recovery in different domains, is easy to use and valid for children aged six years or older, has a low patient refusal rate, can be administered face-to-face or over the telephone and most importantly allows the assessment of the effects of surgery from both clinician and patient perspectives. ${ }^{12-14}$

An observational study using the Portuguese version of the PostopQRS was conducted with the objective of primarily assessing the quality of recovery in patients treated with different neuromuscular blocking reversal agents and validation as an exploratory objective.

\section{MATERIAL AND METHODS}

\section{The PostopQRS}

The PostopQRS was originally developed by a research group of nine anaesthesiologists and two neuropsychologists, with the assistance of one statistician. The initial validation focused on feasibility and face validation, and included 701 patients from eight countries
(Australia, Canada, France, Germany, Mexico, United Kingdom, United States and China). ${ }^{12}$ The acronym for the scale (PQRS) was changed by the authors to PostopQRS in 2014 (personal communication Colin Royse).

Content validation was performed by the PostopQRS authors using the process described previously. ${ }^{12}$

In this study, content validation was assumed and no further testing for content validation in Portuguese was conducted.

A forward-backward translation of the initial version was performed by Marques $\mathrm{A}$ and a panel of Portuguese anaesthesiologists using the guidelines proposed by Guillemin et al, ${ }^{15,16}$ which was then accepted by the authors of the original scale (see appendix for the questionnaire used) (Appendix 1: https://www.actamedicaportuguesa. com/revista/index.php/amp/article/view/9451/Appendix_01. pdf).

The six domains of recovery included in the PostopQRS instrument ${ }^{12}$ are shown in Table 1. Baseline measurements of the PostopQRS were conducted up to 14 days before surgery. After the end of surgery the PostopQRS was repeated at 15 minutes (T15), 40 minutes (T40) and also at days 1 (D1) and 3 (D3). The PostopQRS was conducted face-to-face for baseline, T15, T40 and D1 and D3 assessments if the patient was still in hospital; otherwise it was conducted via telephone interview once the patient was discharged. PostopQRS is not a summative score, it indicates whether patients have either recovered or not based on, at least, the return to baseline in each domain.

Following a human volunteer study, the cognitive scoring was modified by including a tolerance factor for each question to account for normal performance variability. ${ }^{18}$ In this analysis the original cognitive scoring technique was used to be consistent with the previous publication of this dataset, ${ }^{17}$ and the original validation study. ${ }^{12}$

\section{Design and study population}

A convenience sample of 101 adult patients (18 years or older) undergoing elective surgery requiring general anaesthesia with non-depolarising muscle relaxants and the use of neuromuscular blockade (NMB) reversal agents (neostigmine or sugammadex) at two Portuguese tertiary centres (Hospital de Santo António in Porto and Hospital da Luz in Lisboa) participated in the study from June to November 2012. The choice of drugs used for pre-medication and anaesthesia as well as the use of neuromuscular transmission monitoring was left to the discretion of the anaesthesiologist in charge of the patient. Neostigmine was routinely used as a NMB reversal drug by anaesthesiologists from Hospital de Santo António, and sugammadex was routinely used as a reversal agent by anaesthesiologists from Hospital da Luz. Both hospitals, however, had similar protocols for anaesthesia, analgesia, and management of postoperative nausea and vomiting. All participants were Portuguese native speakers and included male and female patients, aged 18 years or older, scheduled for otolaryngology, gynaecological and abdominal elective 
surgical procedures. Exclusion criteria were American Society of Anesthesiologists (ASA) physical status $\geq 4$ and the presence of any psychiatric disease that interfered with the patient's decision and ability to participate. The study was conducted in daily practice conditions. ${ }^{17}$ The study protocol was approved by the Ethics Committee of the participating hospitals: Ethical Committee of Hospital de Santo António, Porto, Portugal on 11 June 2012 and by the Ethical Committee of Hospital da Luz, Lisboa, Portugal on 31 May 2012. All patients gave written informed consent. This paper reports the subanalysis of the previous study but related to instrument validation. ${ }^{17}$

The PostopQRS was administered face-to-face during the patient's stay in the hospital and by telephone after discharge, mostly at D3 timepoint. The telephone contact was included to capture time points after hospital discharge, sparing the patient the burden and cost of an additional hospital visit to perform the tests. To help standardize the telephone assessment, the 'faces' diagrams pertaining to questions were supplied to the patients to use at home. Physiological domain was not assessed at D3. The nine items of the physiological domain were scored at three levels (3: values fell into accepted ranges; 2: abnormal values; 1 : extremely abnormal values). Pain intensity and nausea (nociceptive domain) were scored using a 1-5 rating scale with the use of a 'faces' pictorial display to aid ease of response. Muscle strength evaluation was performed using a handgrip dynamometer (MAP Kern \& Sohn $\mathrm{GmbH}$, Waagen \& Gewichte, Lüdenscheit, Germany).

\section{Data collection and psychometric evaluation}

A detailed description of data collected for each patient according to the study protocol has been previously reported. ${ }^{17}$ PostopQRS response rates were expressed as the percentage of patients that attempted the survey at T15, T40, D1, and D3, except for physiologic domain which was not measured at D3 evaluation, and activities of daily living which was not evaluated at T15. Scoring was done according to the original scale (Table 1). ${ }^{12}$ Muscle strength was measured at baseline and at T15, T40 and D1.

The validation process of the Portuguese version of the PostopQRS included construct validity, reliability, responsiveness, feasibility and acceptability, which are detailed in Table $2 .{ }^{18-20}$ Criterion validity was not applicable as there was no 'gold standard' available to be considered. Test-retest reliability was not applicable given that observations were performed at specific time points after surgery, where changes in score were anticipated.

\section{Statistical analysis}

Between-group comparisons (e.g., recovered versus not recovered) regarding quantitative variables (e.g., age) were performed using the Student's $t$ test for independent samples or the Mann-Whitney $U$ test when data were not normally distributed. Categorical variables were compared with the chi-square $\left(\chi^{2}\right)$ test, the Cochran-Mantel-Haenszel analysis or the Fisher's exact test when appropriate. The Cochran-Mantel-Haenszel test was used to compare group differences over multiple time points. A comparison of the proportion of recovery in each domain between T15 and

Table 1 - Six PostopQRS domains of recovery

\begin{tabular}{|c|c|c|}
\hline Domain & Recovery parameters measured & Comment \\
\hline Physiology & $\begin{array}{l}\text { Systolic blood pressure, heart rate, } \\
\text { temperature, respiratory rate, and } \\
\text { oxygen saturation, airway control, level } \\
\text { of agitation, level of consciousness, and } \\
\text { activity on command relate to emergence } \\
\text { and airway safety. }\end{array}$ & $\begin{array}{l}\text { This domain is tested in the immediate and early } \\
\text { period. It is principally designed to assess physiologic } \\
\text { safety and 'home readiness' for day-stay surgery. } \\
\text { Recovery in this domain was classified into three } \\
\text { levels: } \\
3 \text { - Values under accepted ranges; } \\
2 \text { - Abnormal levels; } \\
1 \text { - Extremely abnormal levels. } \\
\text { These levels were derived from literature. }{ }^{12}\end{array}$ \\
\hline Nociceptive & $\begin{array}{l}\text { Patient assesses of pain and nausea at } \\
\text { the time of testing. }\end{array}$ & $\begin{array}{l}1-5 \text { rating scale use a 'faces' pictorial display to aid } \\
\text { ease of response. }\end{array}$ \\
\hline Emotional & $\begin{array}{l}\text { Patient assesses of feelings of anxiety and } \\
\text { depression at the time of measurement. }\end{array}$ & Scoring is the same as for nociceptive domain. \\
\hline Activities of daily living & $\begin{array}{l}\text { Assesses physical return to normalcy } \\
\text { through activities of daily living: ability to } \\
\text { stand, walk and dress without assistance, } \\
\text { and ability to eat and drink. }\end{array}$ & $\begin{array}{l}\text { Scored as } 3=\text { easily, } 2=\text { with difficulty, and } 1=\text { not } \\
\text { at all. }\end{array}$ \\
\hline Cognitive & $\begin{array}{l}\text { Five tests assess orientation, verbal } \\
\text { memory, executive functioning, attention, } \\
\text { and concentration. }\end{array}$ & $\begin{array}{l}\text { Tests produce performance scores. The tests } \\
\text { are derived from validated and extensively used } \\
\text { neurocognitive tests that include asking patient's } \\
\text { information like the city they are currently, name and } \\
\text { date of birth. Memorizing and repeating exercises of } \\
\text { numbers and words are also part of the procedure. }{ }^{12}\end{array}$ \\
\hline Overall patient perspective & $\begin{array}{l}\text { Patients rate of their recovery with respect } \\
\text { to their activities of daily living, clarity of } \\
\text { thought, ability to work, and satisfaction } \\
\text { with anaesthetic care. }\end{array}$ & $\begin{array}{l}\text { Reported on a } 5 \text {-point scale in the same manner as } \\
\text { nociceptive. Return to work is only applied to those } \\
\text { who currently work and intend to return to work after } \\
\text { surgery.* }\end{array}$ \\
\hline
\end{tabular}

* This domain is complimentary to the other recovery domains but is not included in the analysis of return to baseline 
Table 2 - Steps and procedures followed in the validation process of the PostopQRS

\begin{tabular}{|c|c|c|}
\hline $\begin{array}{l}\text { Validation process } \\
\text { steps }\end{array}$ & Definition & Procedures and assumptions \\
\hline Content validity & $\begin{array}{l}\text { A judgement whether the scale } \\
\text { samples all the relevant or important } \\
\text { contents or domains }\end{array}$ & $\begin{array}{l}\text { PostopQRS process of development of the scale by authors of the } \\
\text { original study }\end{array}$ \\
\hline \multirow[t]{3}{*}{ Construct validity } & \multirow{3}{*}{$\begin{array}{l}\text { A construct is a theory to explain the } \\
\text { relationship between two or more } \\
\text { variables; if the instrument being } \\
\text { tested provides results supporting } \\
\text { the constructs (that were based on } \\
\text { the previous scientific knowledge) } \\
\text { then these support its validity - the } \\
\text { instrument measures what was } \\
\text { intended to }\end{array}$} & $\begin{array}{l}\text { Construct 1: The overall percentage of patients showing recovery in } \\
\text { each domain of the Portuguese version of the PostopQRS tended to } \\
\text { increase with time }\end{array}$ \\
\hline & & $\begin{array}{l}\text { Construct 2: Proportion of patients recovering over time by domains } \\
\text { at each time point are different according to patient gender for ENT } \\
\text { and general surgery procedures }\end{array}$ \\
\hline & & $\begin{array}{l}\text { Construct 3: The percentage of patients recovered on each of } \\
\text { the Portuguese version of PostopQRS domains is associated with } \\
\text { changes of muscle strength (muscle strength was evaluated as a } \\
\text { potential surrogate marker for neuromuscular recovery) }\end{array}$ \\
\hline Reliability & $\begin{array}{l}\text { Magnitude of error inherent to each } \\
\text { measurement instrument }\end{array}$ & Cronbach's alpha when appropriate \\
\hline Responsiveness & $\begin{array}{l}\text { The ability of an instrument to measure } \\
\text { a meaningful or clinically important } \\
\text { change in a clinical state }\end{array}$ & $\begin{array}{l}\text { Proportion of patients recovering over time by domains at specific } \\
\text { time points are different according to the use of different NMB } \\
\text { reversal agents: neostigmine versus sugammadex (= construct } 3 \text { ) }\end{array}$ \\
\hline Feasibility & $\begin{array}{l}\text { Ease of use for users applying the } \\
\text { scale }\end{array}$ & $\begin{array}{l}\text { The median time to conduct the Portuguese version of the test at } \\
\text { baseline and postoperatively }\end{array}$ \\
\hline Acceptability & Capacity of being accepted & $\begin{array}{l}\text { Time taken to complete the full PostopQRS and successful } \\
\text { completion rate }\end{array}$ \\
\hline
\end{tabular}

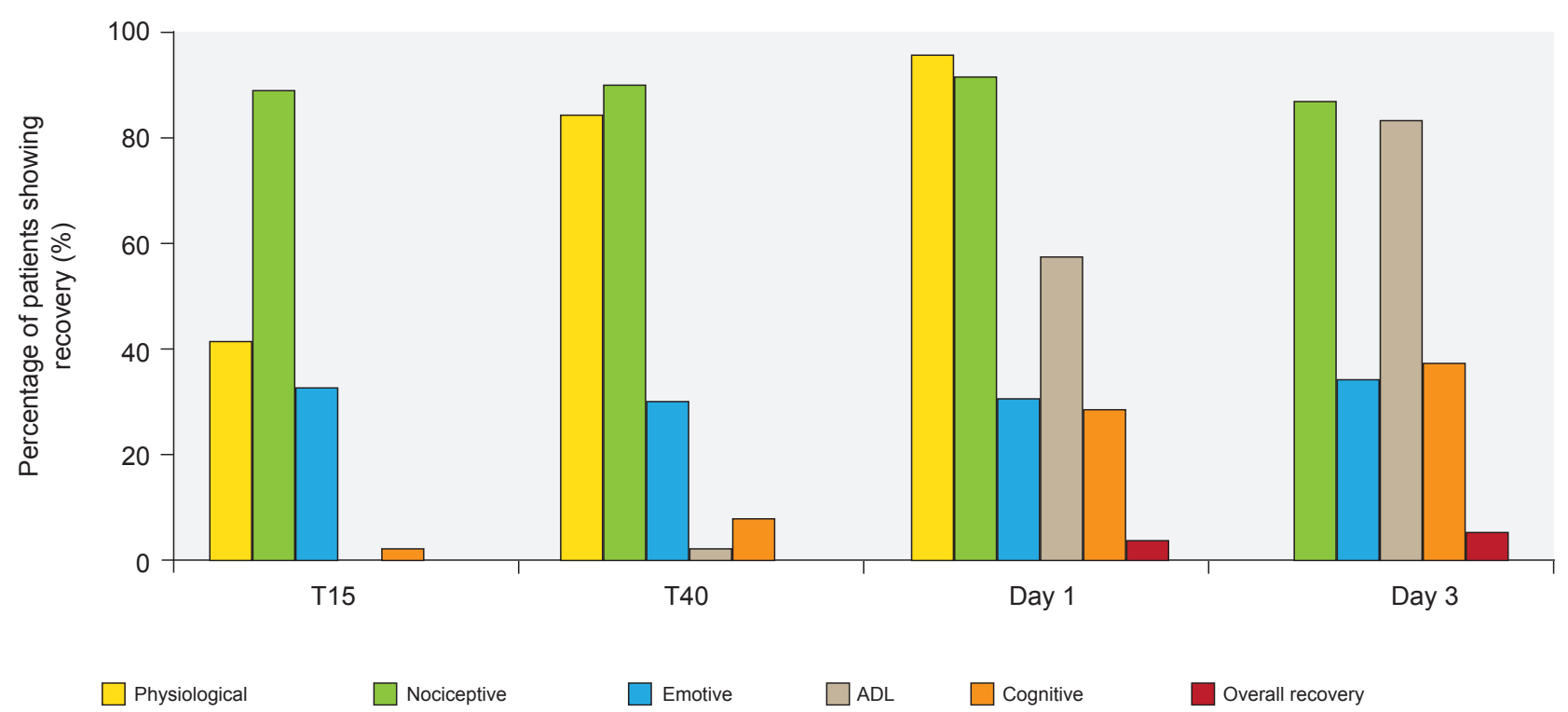

Figure 1 - Percentage of patients showing recovery by PostopQRS domain, evaluated at 15 and 40 min, one and three days

ADL: Activities of daily living.

the last evaluation was assessed using the McNemar's test. Internal consistency of the Portuguese version of PostopQRS was only evaluated for cognition and activities of daily living domains since for the remainder the scale used do not allow use of Cronbach's alpha coefficient. Data were analyzed with the Statistical Package for the Social Sciences (SPSS; version 18 IBM) statistical software program.

\section{RESULTS}

\section{Study patients}

The study population included 32 men and 69 women, with a mean (SD) age of 45.7 (13.0) years. The mean surgery and anaesthesia duration was 68 (40) minutes and 99.4 (45.4) minutes, respectively. The surgery route was laparotomy in $17 \%$ of patients, laparoscopy in $56 \%$ and other in $27 \%$. Surgical operations included general abdominal procedures in $49 \%$ of patients, gynaecological in $24 \%$ and otolaryngological in $27 \%$. The median (range) muscle strength, at baseline, was 24.8 (6.2 - 173.0) kilogram-force. The time taken to complete the scale ranged from minimum 262 (81) seconds at T15 to maximum 360 (95) seconds at D1. Of the 101 patients included in the study, reversal of neuromuscular blockade induced by rocuronium (87\%), 
vecuronium (1\%) or other agents (12\%), was accomplished by treating with neostigmine $(47.5 \%)$ and sugammadex $(52.5 \%)$.

\section{Construct validity}

Three constructs were assessed.

Construct 1: The overall percentage of patients showing recovery in each domain of the Portuguese version of the PostopQRS tended to increase with time. For the entire study population, the percentage of patients showing overall recovery and per each domain of the Portuguese version of the PostopQRS tended to increase with time (Fig. 1).
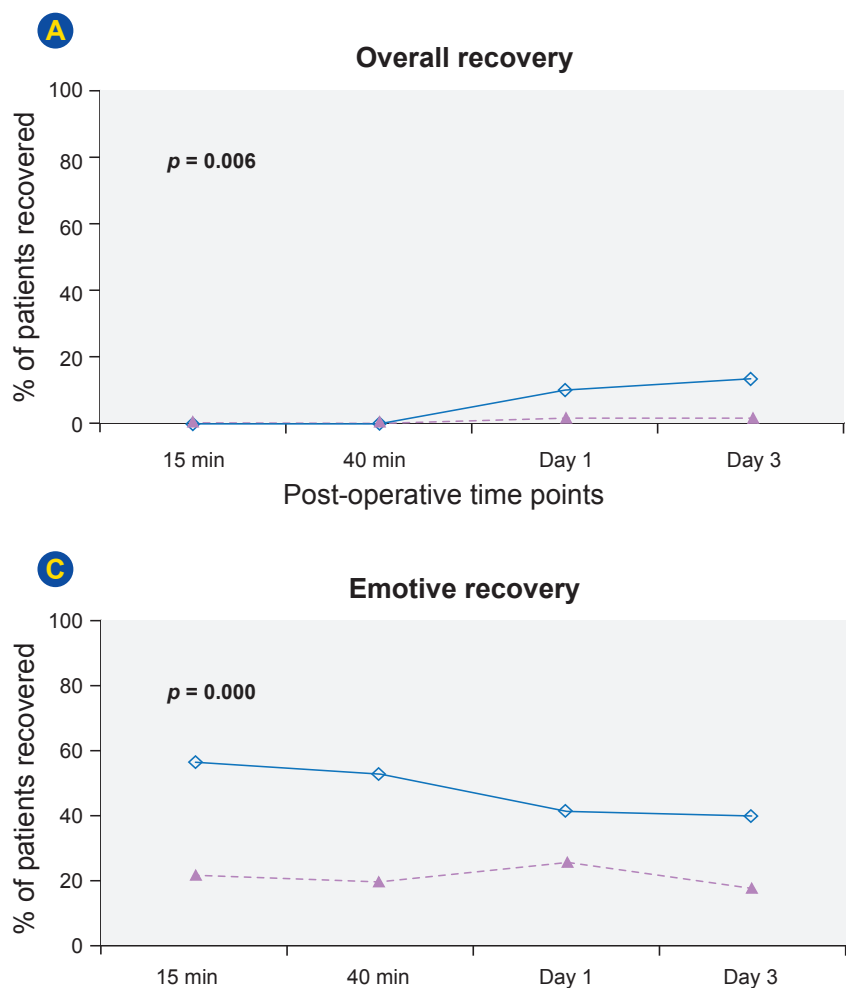

Post-operative time points

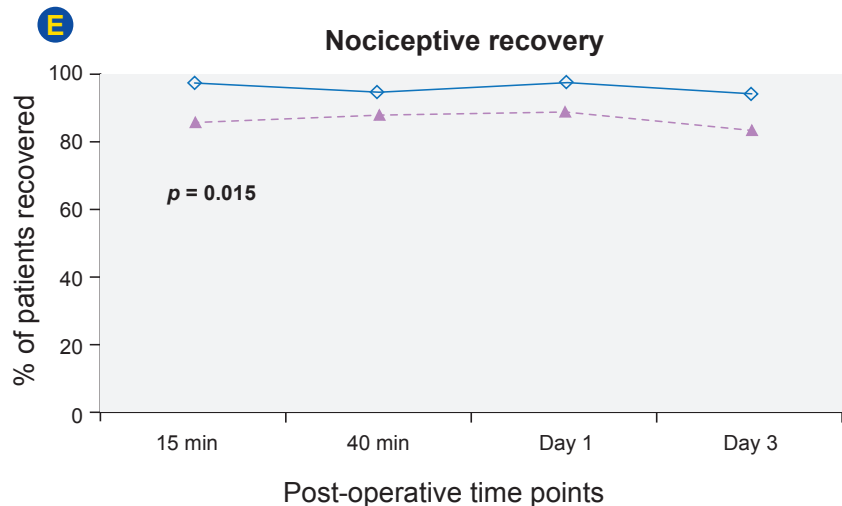

Construct 2: Proportion of patients recovering over time by domains at each time point are different according to patient gender for ENT (ear, nose and throat) and general surgery procedures. A comparison of recovery according to gender is shown in Figs. 2 to 4 . In the full cohort, (Fig. 2 ), recovery was lower for female patients over time in the emotive domain $(p=0.000)$, most prominently at T15 and T40 after surgery. Recovery was also lower in female patients for the nociceptive domain $(p=0.015)$, activities of daily living ( $p=0.001)$ and overall recovery $(p=0.006)$. Sub-analysis (Figs. 3 and 4 ) according to surgery type showed lower recovery for female patients over time for both general surgery and ENT surgery in the emotive domain
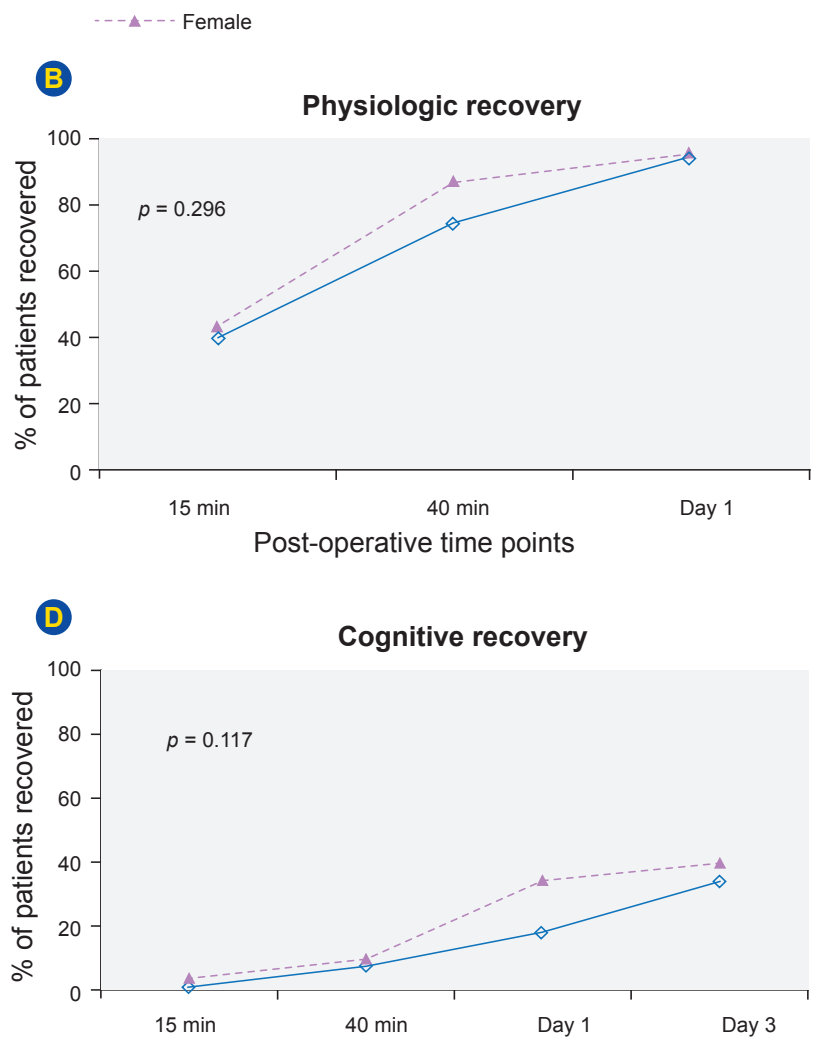

Post-operative time points

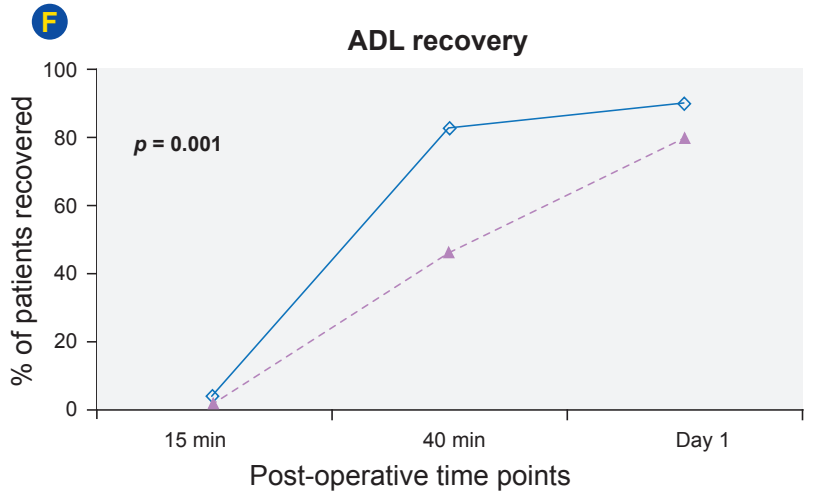

Figure 2 - Percentage of patients showing recovery by PostopQRS domain and by gender in the full cohort. Times are 15 and 40 min, 1 and 3 days. $p$-value was calculated using the Cochran-Mantel-Haenszel test.

ADL: Activities of daily living. 
( $p=0.011$ and $p=0.002$, respectively) and the nociceptive domain ( $p=0.025$ and $p=0.03$, respectively). However, for activities of daily living this was only observed among patients undergoing general surgery procedures $(p=0.01)$.

Construct 3: The percentage of patients recovered on each of the Portuguese version of PostopQRS domains is associated with changes of muscle strength. At T15, the median change of muscle strength from baseline was lower for patients who had not recovered in the physiological domain (-8.40 kgf vs $-5.20 \mathrm{kgf} ; p=0.040)$; and at D1, patients that had not recovered in the cognitive domain had lower muscle strength (-1.30 kgf vs $0.40 \mathrm{kgf} ; p=0.007)$.

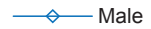

A

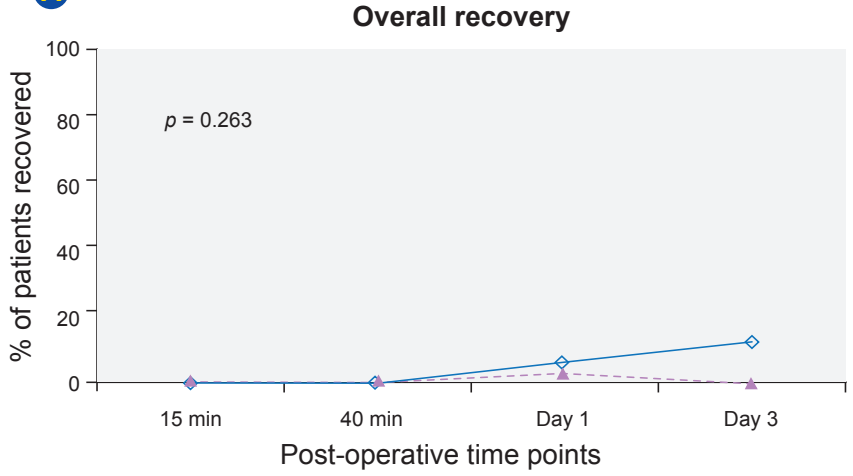

C

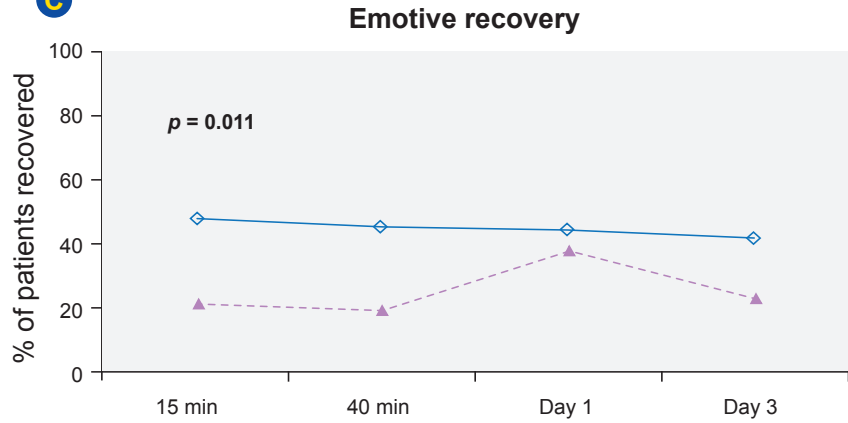

Post-operative time points

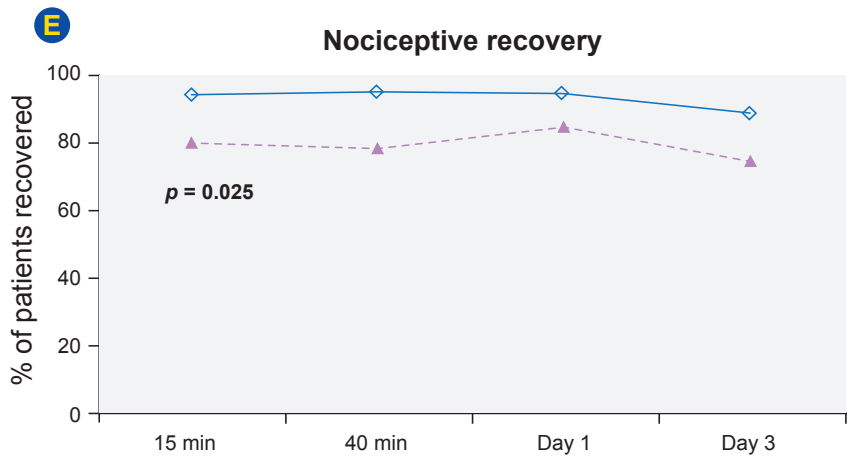

Post-operative time points

\section{Reliability}

The internal consistency of the Portuguese version of PostopQRS for the domain of activities of daily living proved acceptable at all-time points (Cronbach's alpha coefficient value of $1.000,0.772,0.988,1.000$ for T15, T40, D1 and $\mathrm{D} 3$, respectively). On the other hand, internal consistency for the cognition domain showed values of Cronbach's alpha coefficient lower than expected at T0 and T40 (0.505 and 0.565 , respectively) but acceptable for the remaining time points (Cronbach's alpha coefficient value of 1.000 at T15, D1 and D3).

Different assessments of reliability like test-retest were not applied since PostopQRS analyses changes over time.
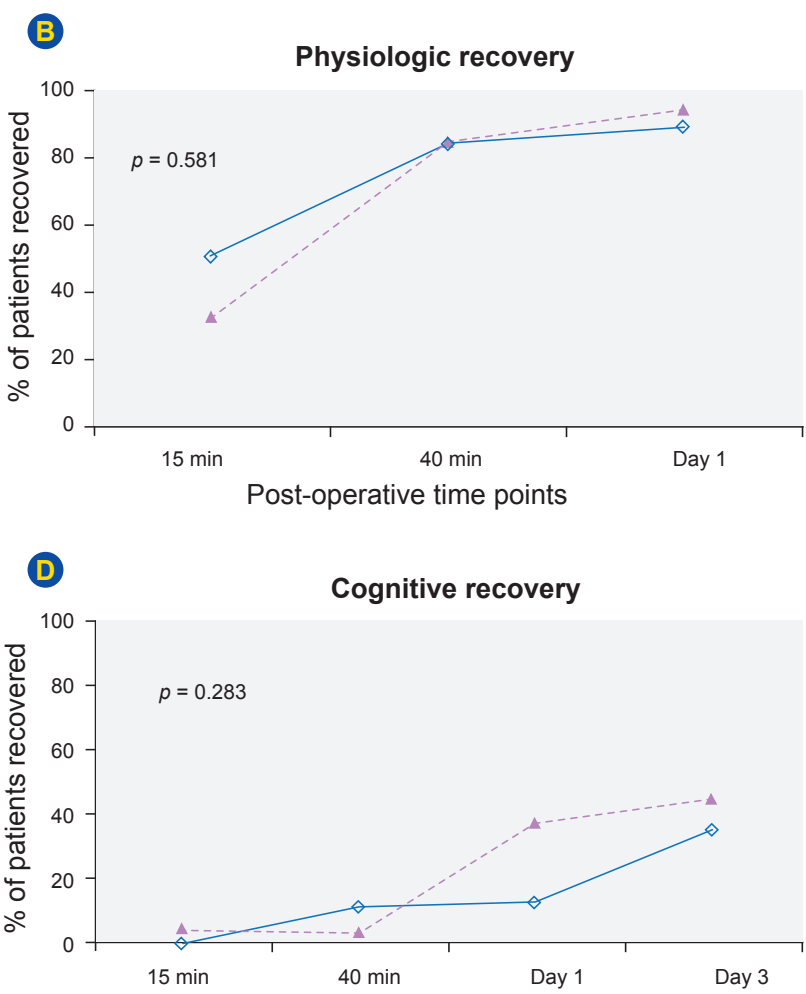

Post-operative time points

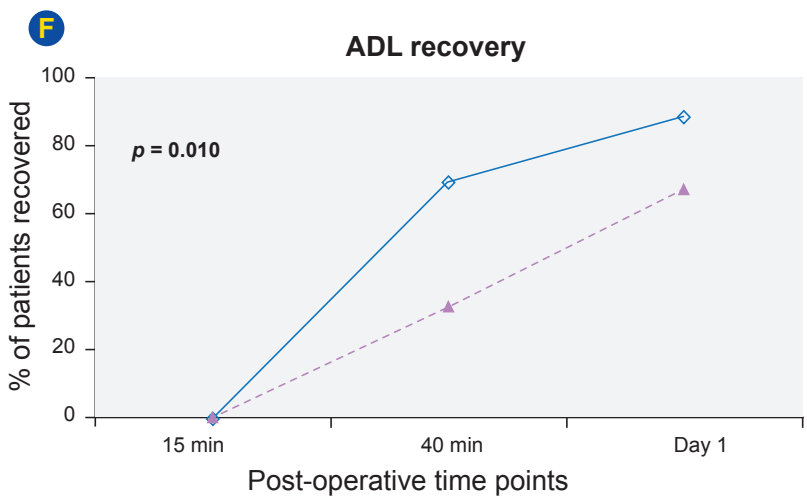

Figure 3 - Percentage of patients undergoing general surgery showing recovery by PostopQRS domain and by gender. Times are 15 and 40 min, 1 and 3 days. $p$-value was calculated using the Cochran-Mantel-Haenszel test. ADL: Activities of daily living. 


\section{Responsiveness}

The Portuguese version of PostopQRS was capable of detecting significant differences in postoperative quality recovery between the NMB reversal agents, sugammadex and neostigmine (Fig. 5). ${ }^{17}$ Recovery over time was better for sugammadex versus neostigmine in the physiologic and nociceptive domains ( $p=0.027$ and $p=0.002$ ) with the greatest differences at T15 and T40, whereas recovery was higher in the emotive domain for neostigmine $(p=0.046)$ with the greatest differences at T40 and D3.

For both general surgery and ENT procedures subgroups (Tables 3 and 4), physiological domain recovery was higher for sugammadex at T40: general surgery $(100 \%$ vs $75.8 \%, p=0.041)$ and ENT procedures $(100 \%$ vs $57.1 \%$, $p=0.017$ ).

\section{Feasibility and acceptability}

The median (range) time in seconds to perform the PostopQRS assessments was 319 (95 - 581) seconds at baseline, 263 (85 - 525) seconds at T15, 305 (110 - 517) seconds at T40, 291 (135 - 491) seconds at D1 and 252 (106 - 410) seconds at D3. The percentage of patients that completed all items for all domains was $87 \%(95 \% \mathrm{Cl} ; 79 \%$ - 93\%) at T15, 75\% (95\% Cl; 66\% - 83\%) at T40, 65\% (95\% $\mathrm{Cl} ; 55 \%-75 \%)$ at D1 and $94 \%(95 \% \mathrm{Cl} ; 87 \%-98 \%)$ at D3.
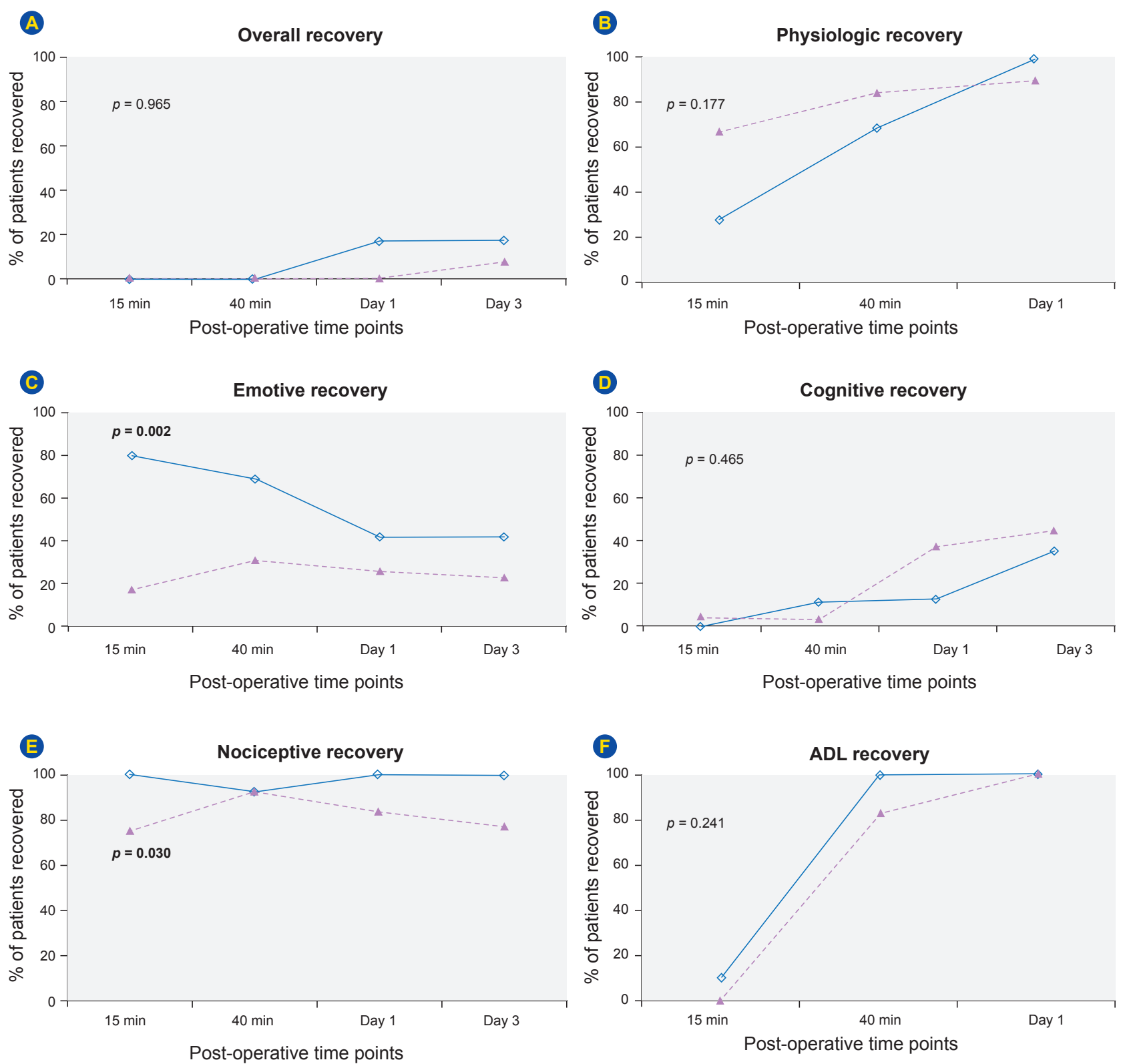

Figure 4 - Percentage of patients undergoing ENT surgery showing recovery by PostopQRS domain and by gender. Times are 15 and 40 min, 1 and 3 days. $p$-value was calculated using the Cochran-Mantel-Haenszel test.

$A D L$ : Activities of daily living. 

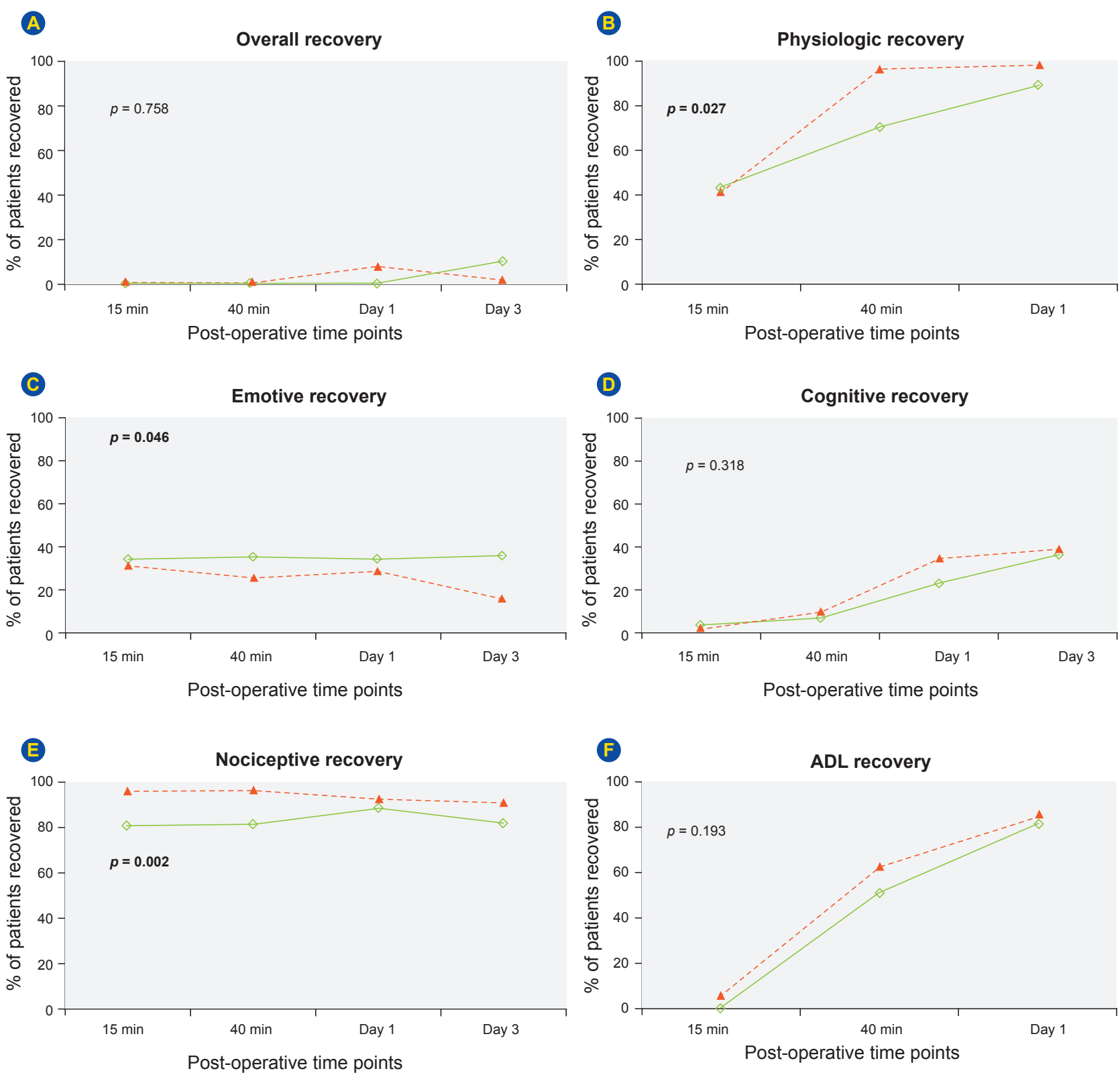

Figure 5 - Percentage of patients showing recovery by PostopQRS domain and by NMB reversal agent. Times are 15 and 40 min, 1 and 3 days. $p$-value was calculated using the Cochran-Mantel-Haenszel test.

ADL: Activities of daily living.

\section{DISCUSSION}

This study shows that the Portuguese version of the PostopQRS, ${ }^{12}$ demonstrates construct validity, reliability, responsiveness, feasibility and acceptability.

The internal consistency of the Portuguese version of PostopQRS for the domain of activities of daily living proved acceptable at all-time points. Cronbach's alpha coefficient values above 0.9 may suggest some item redundancy but, we believe, this is a minor problem and did not affect the validation process..$^{19}$ On the other hand, internal consistency for the cognition domain showed values of Cronbach's alpha coefficient lower than expected at T0 and T40 but acceptable for the remaining time points. As construct validity was proven, the lower values do not seem crucial.

The first construct is that recovery should improve over time, which was shown using the Portuguese version, and is consistent with the findings of the original PostopQRS validation paper. ${ }^{12}$

For construct 2 (effects of gender on recovery) we found worse recovery for females that was not dependent on the type of surgery. However, cognitive recovery was not affected and this is consistent with the findings of Lindqvist et $a^{R^{1}}$ using PostopQRS at 30 and 90 minutes in patients undergoing elective surgery under general anaesthesia. In a sub-analysis of the PostopQRS feasibility study, focussing on cognition, gender was not assessed as a variable, and 
does not allow comparison with this construct. ${ }^{22}$

For construct 3 we considered that the percentage of patients recovered on each of the Portuguese version of PostopQRS domains is related with muscle strength recovery, as muscle strength was assumed as a potential surrogate marker for neuromuscular recovery. We were also able to show association between muscle strength for the physiological and cognitive domains while studying construct 3 (so recovery is associated with muscle strength for those domains). Although no other study assessing this construct was found the assumption seemed plausible.

Royse et al showed discriminant validation for the PostopQRS patients undergoing tonsillectomy and nasal surgery ${ }^{14}$ and reported a worse recovery profile over the first three days in nociceptive, activities of daily living and overall recovery for the group of tonsillectomy patients as compared to nasal surgery patients. ${ }^{14}$ In our study, when assessing responsiveness (recovery is different according to muscle relaxant reversal agent) we were able to discriminate between sugammadex versus neostigmine for both general surgery and ENT procedures.

The other components of validation were acceptable and similar to published date of the English version. ${ }^{12}$

In the present study, a convenience sample of patients undergoing elective surgery at two different hospitals in Portugal was used, which could introduce inclusion bias. We attempted to reduce this by performing analyses on groups that were similar (type of surgery or gender). Content validity, or the extent to which the measurement incorporates the domain of the phenomena under study, was assumed as the process has been published with the original PostopQRS validation paper. ${ }^{12}$ We did not further consider this aspect of validation. Criterion validity or the extent to which the measurement correlates with an external criterion of the phenomenon under study, was not examined, given that there is no 'gold standard available' to be considered.

Table 3 - Overall recovery rates and recovery rates of patients undergoing General Surgery by PostopQRS domains and by reversal NMB agent at different time intervals (15 and $40 \mathrm{~min}, 1$ and 3 days)

\begin{tabular}{|c|c|c|c|}
\hline \multirow{2}{*}{ General Surgery } & \multicolumn{2}{|c|}{ NMB reversal agent } & \multirow{2}{*}{$p$-value } \\
\hline & Neostigmine & Sugammadex & \\
\hline \multicolumn{4}{|l|}{ T15 } \\
\hline Overall recovery & $0.0(34 / 34)$ & $0.0(16 / 16)$ & - \\
\hline Physiological & $39.4(13 / 33)$ & $37.5(6 / 16)$ & $0.898^{*}$ \\
\hline Nociceptive & $80.0(24 / 30)$ & $93.8(15 / 16)$ & $0.394^{* *}$ \\
\hline Emotive & $30.0(9 / 30)$ & $31.3(5 / 16)$ & $1.000^{* *}$ \\
\hline Cognitive & $3.3(1 / 30)$ & $0.0(0 / 16)$ & $1.000^{* *}$ \\
\hline \multicolumn{4}{|l|}{ T40 } \\
\hline Overall recovery & $0.0(34 / 34)$ & $0.0(16 / 16)$ & - \\
\hline Physiological & $75.8(25 / 33)$ & $100.0(16 / 16)$ & $0.041^{* *}$ \\
\hline Nociceptive & $79.4(27 / 34)$ & $93.8 / 15 / 16)$ & $0.409^{* *}$ \\
\hline Emotive & $29.4(10 / 34)$ & $26.7(4 / 15)$ & $1.000^{* *}$ \\
\hline Cognitive & $8.8(3 / 34)$ & $0.0(0 / 16)$ & $0.542^{* *}$ \\
\hline Activities of daily living & $100.0(33 / 33)$ & $100.0(8 / 8)$ & - \\
\hline \multicolumn{4}{|l|}{ D1 } \\
\hline Overall recovery & $0.0(32 / 32)$ & $12.5(2 / 16)$ & $0.106^{* *}$ \\
\hline Physiological & $81.8(9 / 11)$ & $100.0(13 / 0)$ & $0.199^{* *}$ \\
\hline Nociceptive & $87.5(28 / 32)$ & $87.5(14 / 16)$ & $1.000^{* *}$ \\
\hline Emotive & $37.5(12 / 20)$ & $43.8(7 / 9)$ & $0.676^{*}$ \\
\hline Cognitive & $21.9(7 / 32)$ & $43.8(7 / 16)$ & $0.178^{* *}$ \\
\hline Activities of daily living & $38.7(12 / 31)$ & $56.3(9 / 16)$ & $0.252^{*}$ \\
\hline \multicolumn{4}{|l|}{ D3 } \\
\hline Overall recovery & $6.9(2 / 29)$ & $0.0(15 / 15)$ & $0.540^{* *}$ \\
\hline Nociceptive & $75.9(22 / 29)$ & $86.7(13 / 15)$ & $0.695^{* *}$ \\
\hline Emotive & $37.9(11 / 29)$ & $13.3(2 / 15)$ & $0.162^{* *}$ \\
\hline Cognitive & $37.9(11 / 29)$ & $46.7(7 / 15)$ & $0.576^{*}$ \\
\hline Activities of daily living & $72.4(21 / 29)$ & $80.0(12 / 15)$ & $0.722^{* *}$ \\
\hline
\end{tabular}

Data expressed in percentages (recovered patients/total patients).

* Pearson chi-square: ** Fisher's exact test 
Table 4 - Overall recovery rates and recovery rates of patients undergoing ENT Procedure by PostopQRS domains and by reversal NMB agent at different time intervals ( 15 and 40 min, 1 and 3 days)

\begin{tabular}{|c|c|c|c|}
\hline \multirow{2}{*}{ ENT procedure } & \multicolumn{2}{|c|}{ NMB reversal agent } & \multirow{2}{*}{$p$-value } \\
\hline & Neostigmine & Sugammadex & \\
\hline \multicolumn{4}{|l|}{ T15 } \\
\hline Overall recovery & $0.0(11 / 11)$ & $0.0(12 / 12)$ & - \\
\hline Physiological & $50.0(6 / 6)$ & $45.5(5 / 11)$ & $0.827^{*}$ \\
\hline Nociceptive & $81.8(9 / 11)$ & $90.9(10 / 11)$ & $1.000^{* *}$ \\
\hline Emotive & $45.5(5 / 11)$ & $45.5(5 / 11)$ & $1.000^{*}$ \\
\hline Cognitive & $0.0(11 / 11)$ & $0.0(11 / 11)$ & - \\
\hline \multicolumn{4}{|l|}{$\mathrm{T} 40$} \\
\hline Overall recovery & $0.0(14 / 14)$ & $0.0(12 / 12)$ & - \\
\hline Physiological & $57.1(8 / 14)$ & $100.0(12 / 12)$ & $0.017^{* *}$ \\
\hline Nociceptive & $85.7(12 / 14)$ & $100.0(12 / 12)$ & $0.483^{* *}$ \\
\hline Emotive & $50.0(7 / 14)$ & $50.0(6 / 12)$ & $1.000^{*}$ \\
\hline Cognitive & $0.0(14 / 14)$ & $16.7(2 / 12)$ & $0.203^{* *}$ \\
\hline Activities of daily living & $0.0(0 / 11)$ & $11.1(1 / 9)$ & $0.450^{\text {** }}$ \\
\hline \multicolumn{4}{|l|}{ D1 } \\
\hline Overall recovery & $0.0(12 / 12)$ & $16.7(2 / 12)$ & $0.478^{* *}$ \\
\hline Physiological & $100.0(7 / 7)$ & $90.9(10 / 11)$ & $1.000^{* *}$ \\
\hline Nociceptive & $91.7(11 / 12)$ & $91.7(11 / 12)$ & $1.000^{* *}$ \\
\hline Emotive & $25.0(3 / 12)$ & $41.7(5 / 12)$ & $0.667^{* *}$ \\
\hline Cognitive & $25.0(3 / 12)$ & $33.3(4 / 12)$ & $1.000^{* *}$ \\
\hline Activities of daily living & $83.3(10 / 12)$ & $100.0(12 / 12)$ & $0.478^{* *}$ \\
\hline \multicolumn{4}{|l|}{ D3 } \\
\hline Overall recovery & $15.4(2 / 13)$ & $8.3(1 / 12)$ & $1.000^{* *}$ \\
\hline Nociceptive & $92.3(12 / 13)$ & $83.3(10 / 12)$ & $0.593^{* *}$ \\
\hline Emotive & $30.8(4 / 13)$ & $33.3(4 / 12)$ & $0.613^{* *}$ \\
\hline Cognitive & $30.8(4 / 13)$ & $41.7(5 / 12)$ & $0.688^{* *}$ \\
\hline Activities of daily living & $100.0(13 / 13)$ & $100.0(12 / 12)$ & - \\
\hline
\end{tabular}

Data expressed in percentages (recovered patients/total patients).

${ }^{*}$ Pearson chi-square: ** Fisher's exact test

\section{CONCLUSION}

The Portuguese version of the PostopQRS showed satisfactory construct validity, reliability, responsiveness, feasibility and acceptability in evaluating the quality of recovery after surgery in the Portuguese population.

\section{ACKNOWLEDGEMENTS}

Assistance with the study: Medical writing and/or editorial assistance was provided by Carolina Moura and Marta Pulido, freelance editor. This last assistance was funded by Merck Sharp \& Dohme, Lda. Statistical support was provided by Vera Vicente, BSc and Pedro Aguiar (PhD) of Eurotrials - Scientific Consultants, Lisboa and funded by Merck Sharp \& Dohme, Lda.

\section{CONFLICTS OF INTEREST}

Mafalda Nogueira is Medical Advisor at Merck Sharp \& Dohme Lda, Portugal. Colin F Royse, Pedro Amorim, André Biscaia, Nuno Rodrigues, José Bismarck and Simão Esteves have served as a paid lecturer and/or a scientific advisor or consultant to Merck Sharp \& Dohme. Colin Royse is the Chair of the PostopQRS scientific committee. José Bismarck, Nuno Rodrigues, Filipa Lagarto and Blandina Gomes have received Study related investigator fees.

\section{FINANCIAL SUPPORT}

Merck Sharp \& Dohme, Lda provided financial support for the non-interventional study (Protocol Nr MK8616-081).

\section{REFERENCES}

1. Wu CL, Richman JM. Postoperative pain and quality of recovery. Curr Opin Anaesthesiol. 2004; 17:455-60.

2. Lee A, Lum ME. Measuring anaesthetic outcomes. Anaesth Intensive Care. 1996;24:685-93.

3. Kluivers KB, Riphagen I, Vierhout ME, Brölmann HA, de Vet HC Systematic review on recovery specific quality-of-life instruments. Surgery. 2008;143:206-15.

4. Mellin-Olsen J, O'Sullivan E, Balogh D, Drobnik L, Knape JT, Petrini 
F. et al. Guidelines for safety and quality in anaesthesia practice in the European Union. Eur J Anaesthesiol. 2007;24:479-82.

5. Hocking G, Weightman WM, Smith C, Gibbs NM, Sherrard K. Measuring the quality of anaesthesia from a patient's perspective: development, validation, and implementation of a short questionnaire. $\mathrm{Br} \mathrm{J}$ Anaesth. 2013;111:979-89.

6. Myles PS, Hunt JO, Nightingale CE, Fletcher H, Beh T, Tanil D, et al. Development and psychometric testing of a quality of recovery score after general anesthesia and surgery in adults. Anesth Analg. 1999;88:83-90.

7. Myles PS, Weitkamp B, Jones K, Melick J, Hensen S. Validity and reliability of a postoperative quality of recovery score: the QoR-40. Br J Anaesth. 2000;84:11-5.

8. Gornall BF, Myles PS, Smith CL, Burke JA, Leslie K, Pereira MJ, et al. Measurement of quality of recovery using the QoR-40: a quantitative systematic review. Br J Anaesth. 2013;111:161-9.

9. Karaman S, Arici S, Dogru S, Karaman T, Tapar H, Kaya Z et al. Validation of the Turkish version of the Quality of Recovery-40 questionnaire. Health Qual Life Outcomes. 2014;12:8.

10. Stark PA, Myles PS, Burke JA. Development and psychometric evaluation of a postoperative quality of recovery score: the QoR-15. Anesthesiology. 2013;118:1332-40.

11. Chanthong P, Abrishami A, Wong J, Herrera F, Chung F. Systematic Review of Questionnaires Measuring Patient Satisfaction in Ambulatory Anesthesia. Anesthesiology. 2009;110:1061-7.

12. Royse CF, Newman S, Chung F, Stygall J, McKay RE, Boldt J, et al. Development and feasibility of a scale to assess postoperative recovery: the post-operative quality recovery scale. Anesthesiology. 2010;113: 892-905.

13. Royse CF, Chung F, Newman S, Stygall J, Wilkinson DJ. Predictors of patient satisfaction with anaesthesia and surgery care: a cohort study using the Postoperative Quality of Recovery Scale. Eur J Anaesthesiol.
2013;30:106-10

14. Royse CF, Williams Z, Purser S, Newman S. Recovery after nasal surgery vs. tonsillectomy: discriminant validation of the Postoperative Quality of Recovery Scale. Acta Anaesthesiol Scand. 2014;58:345-51.

15. Marques A, Marques $C$, Moinho N, Loureiro $C$. Escala de qualidades da recuperação pós-operatória (PQRS) contributos na tradução, verificação da exequibilidade e validação aparente [Postoperative Quality Recovery Scale (PQRS): contributions in translation, feasibility verification and apparent validation]. Rev Soc Port Anesthesiol. 2013;22:S32.

16. Guillemin F, Bombardier C, Beaton D. Cross-cultural adaptation of health-related quality of life measures: Literature review and proposed guidelines. J Clin Epidemiol. 1993;46:1417-32.

17. Amorim P, Lagarto F, Gomes B, Esteves S, Bismarck J, Rodrigues N et al. Neostigmine vs. sugammadex: observational cohort study comparing the quality of recovery using the Postoperative Quality Recovery Scale. Acta Anaesthesiol Scand. 2014;58:1101-10.

18. Royse C, Newman S, Williams Z, Wilkinson D. A Human Volunteer Study to Identify Variability in Performance in the Cognitive Domain of the Postoperative Quality of Recovery Scale. Anesthesiology. 2013;119:576-81.

19. Streiner DL, Norman GR. Health measurement scales. A practical guide to their development and use. $4^{\text {th }}$ ed. Oxford: Oxford University Press; 2008.

20. Nunnaly J, Bernstein I. Psychometric theory. In: Series in Psychology. $3^{\text {rd }}$ ed. New York: McGraw-Hill; 1994.

21. Lindqvist $M$, Royse $C$, Brattwall $M$, Warrén-Stomberg M, Jakobsson J. Post-operative Quality of Recovery Scale: the impact of assessment method on cognition recovery. Acta Anaesthesiol Scand. 2013;57:130812.

22. Newman S, Wilkinson DJ, Royse CF. Assessment of early cognition recovery after surgery using the Post-operative Quality Recovery Scale. Acta Anaesthesiol Scand. 2014;58:185-91. 